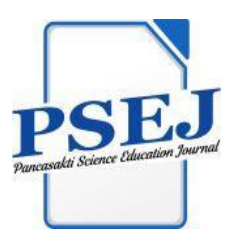

\author{
Pancasakti Science Education Journal \\ PSEJ Volume 4 Nomor 2, Oktober 2019, (Hal. 106 -114) \\ http://scienceeduiournal.org/index.php/PSEJ/issue/view/7 \\ doi: $10.24905 /$ psej. $v 4 i 2.1387$
}

Submitted: 4/10/2019, Accepted: 30/10/2019, Published: 31/10/2019

\title{
Implikasi Kegiatan Partisipatif Program Adiwiyata pada Kampung Binaan (Studi Kasus : SMK N 2 Semarang)
}

\author{
Nanik Hidayati ${ }^{1}$, Marsista Buana Putri ${ }^{2}$ \\ ${ }^{1,2}$ Program Studi Perencanaan Wilayah dan Kota, FTR Universitas Selamat Sri Kendal, Indonesia \\ Email: pwknanik@gmail.com
}

\begin{abstract}
Abstrak
Adiwiyata merupakan program pemerintah di bidang pendidikan sebagai perwujudan tanggungjawab warga negara dalam upaya melindungi dan melestarikan lingkungan. SMKN 2 Semarang sebagai sekolah berpredikat Adiwiyata Mandiri pada tahun 2013 terus berbenah untuk mencetak perilaku peduli lingkungan warga sekolah dan lingkungan sekitarnya. Kegiatan Adiwiyata tidak hanya di sekolah, namun melebar ke kampung sekitar. Penelitian ini bersifat deskriptif kualitatif yang memaparkan partisipasi warga sekolah di kampung binaan agar berperilaku peduli lingkungan. Data dikumpulkan melalui kegiatan observasi, dokumentasi, dan wawancara untuk dicocokkan dengan kegiatan partisipatif Adiwiyata SMKN 2 Semarang di Kampung Rahayu sebagai kampung binaannya. Analisis data dengan tahapan reduksi data, penyajian data, dan penarikan kesimpulan. Hasil penelitian menunjukkan bahwa partisipasi warga SMKN 2 Semarang di Kampung Rahayu sudah merubah perilaku warga kampung untuk peduli lingkungan dengan menjaga kebersihan lingkungan, membuang sampah pada tempatnya, melakukan penghijauan, mengurangi penggunaan plastik dan stereofoam, menghemat listrik dan air, serta memperbaiki sanitasi lingkungan.
\end{abstract}

Kata Kunci: Adiwiyata; Warga Sekolah; Kampung Binaan

\section{Implication of Participative Activities in the Adiwiyata Program \\ (Case Study: SMK N 2 semarang)}

\begin{abstract}
Adiwiyata is government program in education sector as a responsibility in the context of preserving the environment. SMKN 2 Semarang which held the title as Adiwiyata Mandiri in 2013 keep improve itself to create the awareness of the environment for its school member as well as to people living surrounding it. This is a qualitative descriptive research which explain the people participation in the fostered village to have awareness of the environment. The data is gathered through observation, documentation, and interview to be cross-checked with the participation program of Adiwiyata SMKN 2 Semarang in Kampung Rahayu as the fostered village. Data is analyzed bydata reductionprocess, data presentation, and conclusion drawing. The result shows that the participation of the SMKN 2 Semarang member in Kampung Rahayu could changethe people behavior to care more for the environment by keeping the environment clean, throwing the garbage on its shelter, planting more trees, reduce the use of plastic and stereofoam, use water and electricity wisely, and improve the sanitation.
\end{abstract}

Keywords: Adiwiyata; School member; fostered village 


\section{PENDAHULUAN}

Dunia pendidikan memberikan kontribusi besar bagi perkembangan teknologi untuk melahirkan generasi milenium. Namun teknologi yang dikembangkan harus bersifat ramah dan peduli lingkungan dengan prinsip pembangunan berkelanjutan. Oleh sebab itu dunia pendidikan perlu diajarkan tentang pendidikan lingkungan hidup agar dapat menghasilkan ilmuwan yang peduli lingkungan, sebab pendidikan lingkungan hidup memberikan pengetahuan, contoh sikap dan keterampilan kepada siswa untuk peduli lingkungan seperti yang dikutip Stapp et al, 1969; UNESCO, 1977; Davis, 1998 dalam Dave (2012)

"Environmental education aims to equip the individuals with knowledge, attitudes and skills in order to raise concern for the environment and to work toward solutions of environmental problems and the prevention of new ones".

Salah satu bentuk pendidikan lingkungan hidup yang dapat memberikan motivasi serta membiasakan warga sekolah peduli lingkungan yaitu dengan program Adiwiyata yang sudah dicanangkan pemerintah sejak tahun 2006. Adiwiyata merupakan program pemerintah dalam bidang pendidikan untuk mewujudkan warga sekolah yang bertanggungjawab dalam upaya perlindungan dan pengelolaan lingkungan hidup secara berkelanjutan Adanya program Adiwiyata memberikan partisipasi warga sekolah dalam pengelolaan lingkungan tempat tinggal seperti: mengurangi kegiatan yang menghasilkan sampah, menghemat BBM, menghemat kertas, tidak membuang sampah sembarangan serta menghindari pembakaran sampah yang menimbulkan pencemaran (Meyzilia, 2015).

Program Adiwiyata memiliki prinsip partisipatif dan berkelanjutan untuk mendapatkan pengetahuan, norma, serta etika dalam menciptakan kesejahteraan hidup manusia demi mewujudkan pembangunan berkelanjutan. Ada empat indikator dalam pelaksanaan adiwiyata yaitu: kebijakan sekolah berwawasan lingkungan, kurikulum berbasis lingkungan, kegiatan berbasis partisipatif serta pengelolaan sarana pendukung ramah lingkungan. Menurut Bahrudin (2017) indikator tersebut berperan dalam membiasakan dan membentuk karakter perilaku peduli lingkungan pada warga sekolah. Siswa yang dilibatkan pada program Adiwiyata mampu mengikuti pembelajaran lingkungan hidup serta berpartisipasi aktif dalam pengelolaan lingkungan baik di sekolah maupun di lingkungan tempat tinggal (Meyzilia, 2015).

SMKN 2 Semarang sebagai sekolah yang berada di tengah kota mampu mendapatkan predikat Adiwiyata Mandiri pada tahun 2013. Menurut Setyowati (2015) pelaksanaan program sekolah Adiwiyata di SMKN 2 Semarang sudah sesuai dengan standar Kementerian Negara Lingkungan Hidup. Keberhasilan program Adiwiyata di SMKN 2 Semarang didukung oleh kebiasaan, pengetahuan, dan tindakan nyata yang membutuhkan aturan sekolah yang eksplisit, serta manajemen lingkungan yang berkelanjutan (Hidayati, 2014).

SMKN 2 juga membina tiga belas sekolah dan satu desa binaan di sekitar sekolah. Adapun desa yang menjadi binaan SMKN 2 Semarang yaitu Kampung Rahayu Kelurahan Karangturi, Semarang Timur. Kampung Rahayu merupakan kampung yang padat penduduk dan permukiman. Hampir semua bangunan di Kampung Rahayu bergandengan satu dengan yang lain, sampah berserakan di tepi jalan dan rumah warga. Selain itu Kampung Rahayu merupakan kampung yang dilalui sungai yang airnya berwarna kehitaman berasal dari limbah rumah tangga dan industri di kampung sebelah selatannya. 


\section{METODE}

Penelitian yang dilakukan berupa penelitian deskriptif kualitatif untuk memaparkan bagaimana partisipasi warga SMKN 2 Semarang dalam menanamkan perilaku peduli lingkungan pada warga Kampung Rahayu Kelurahan Karangturi Kecamatan Semarang Timur. Penelitian ini mengambil data dari observasi, dokumentasi, dan wawancara dengan warga sekolah maupun warga Kampung Rahayu untuk dicocokkan dengan keadaan di lapangan. Penelitian ini juga akan memaparkan kegiatan Adiwiyata yang dilakukan di SMKN 2 Semarang, serta bagaimana partisipasinya pada kampung binaan. Sumber data berasal dari data primer yang langsung diperoleh dari lapangan, serta data sekunder yang didapat dari pengumpulan sumber tertulis atau dokumen yang berupa peraturan, tata tertib, proposal, foto kegiatan, serta hasil kreativitas. Adapun nara sumber yang diwawancarai yaitu kepala sekolah, guru, karyawan, siswa, kepala desa, serta warga Kampung Rahayu. Analisis data dengan tahapan reduksi data, penyajian data, dan penarikan kesimpulan. Pengecekan keabsahan data dengan teknik triangulasi sumber dengan membandingkan hasil wawancara dari nara sumber.

\section{HASIL DAN PEMBAHASAN}

SMKN 2 Semarang merupakan sekolah yang berada di Jalan Dr. Cipto Mangunkusumo No. 121 A Semarang yang termasuk daerah yang berada di tengah kota yang padat gedung, bangunan, dan lalu lintas. Batas SMKN 2 Semarang yaitu sebelah barat perumahan warga Kampung Baris Kelurahan Karangturi, sebelah selatan berbatasan dengan SMKN 5 Semarang, sebelah timur berbatasan dengan jalan raya Dr. Cipto Mangunkusuma, dan sebelah utara berbatasan dengan bengkel Yamaha. Dengan luas lahan yang terbatas tersebut, namun SMKN 2 Semarang mampu mengelola lingkungan sekolah yang hijau, asri dan sejuk sehingga pada tahun 2013 berhasil menyabet gelar Sekolah Adiwiyata mandiri.
Keberhasilan tersebut tidak terlepas dari peran warga sekolah dan stakeholder, serta lingkungan sekitar sekolah.

Penerapan program Adiwiyata SMKN 2 Semarang mengacu pada empat indikator yaitu: pengembangan kebijakan sekolah berwawasan lingkungan, pengembangan kurikulum berbasis lingkungan, pengembangan kegiatan berbasis partisipatif, serta pengembangan dan pengelolaan sarana pendukung sekolah berwawasan lingkungan (Tim Adiwiyata Tingkat Nasional, 2011).

Dalam pengembangan kebijakan sekolah bewawasan lingkungan SMKN 2 Semarang memasukkan unsur lingkungan pada Visi, Misi, dan Tujuan sekolah dengan mengunggulkan budaya 3R (Reduce, Reuse, dan Recycle) serta 3S (Senyum, Sapa, dan Salam). Budaya ini tidak hanya untuk siswa saja, namun semua warga SMKN 2 Semarang dihimbau untuk menanamkan dan membudayakan sikap peduli lingkungan tersebut.

Menurut salah seorang pembina SMK Hijau, bahwa tindakan reduce seperti mengurangi penggunaan plastik di kantin dengan gelas atau piring, pada bulan pertama mampu menekan timbulnya sampah plastik sampai 25\%, dan akan terus meningkat prosentasenya untuk bulan-bulan berikutnya. Sedangkan untuk kebijakan penghematan kertas dapat mengurangi timbulan kertas sekitar 15 sampai $20 \%$. Adapun kegiatan reuse yang dilakukan SMKN 2 Semarang berupa penggunaan botol minuman dan box makanan sebagai bekal sekolah. Sekolah juga menggunaan barang kemasan isi ulang untuk pembersih kaca, pembersih lantai, desinfekan dan spidol.

SMKN 2 Semarang memiliki banyak kreativitas dari hasil recycle sampah, seperti pembuatan lukisan berbahan pelepah pisang, bubur kertas, kulit bawang, dan kulit telur, kerajinan botol bekas, kerajinan dari kain dan kertas serta kerajinan dari pecahan kaca. Hasil 
kerajinan tersebut biasanya dilombakan, dipamerkan dan dijual, bahkan hasil kerajinannya ada yang berhasil meraih rekor MURI pada tahun 2012 dan rekor LEPRID tahun 2018.

Dalam pengembangan kurikulum berbasis lingkungan, SMKN 2 Semarang sudah mengintegrasikan lingkungan ke dalam beberapa materi pembelajaran, baik yang tertuang dalam silabus dan RPP maupun secara spontan dalam pembelajaran di kelas. Sebagai contoh sebelum pembelajaran dimulai guru memeriksa kebersihan dan kerapian kelas, selesai pembelajaran juga dibiasakan membersihkan kelas beserta whiteboard atau papan tulis. Pada proses pembelajaran ada beberapa materi yang dikaitkan dengan isu lokal maupun global tentang lingkungan.

Pengembangan kegiatan berbasis partisipatif dilakukan di dalam maupun di luar sekolah. Bentuk kegiatan di sekolah berupa piket kelas setiap hari, jumat bersih, penggunaan botol dan box makanan, mengurangi penggunaan plastik dan kertas, serta kegiatan penghijauan sekolah. Dalam kegiatan penghijauan setiap siswa diwajibkan membawa tanaman untuk dibuat taman seperti: Taman Toyota, Taman Kirai, Taman BNI, Taman Therapi, green house, dan warung hidup. SMKN 2 Semarang memanfaatkan $80 \%$ tanahnya untuk lahan terbuka, sedangkan $20 \%$ sisanya untuk bangunan fungsional. Hal tersebut yang membuat SMKN 2 Semarang terkesan sejuk dan asri ditambah kicauan burung-burung yang terbang kesana kemari, meskipun berada di tengah kota.

Partisipasi kegiatan di luar sekolah berupa diikutkannya siswa dalam lomba atau pameran lingkungan, serta bakti sosial di luar sekolah. SMKN 2 Semarang juga membina tiga belas sekolah dan satu kampung binaan di Semarang. Tujuannya untuk menularkan dan mengembangkan sikap dan budaya lingkungan seperti dalam program Adiwiyata. Adapun tolok ukur keberhasilannya yaitu perubahan perilaku dan pembentukan karakter peduli lingkungan. Kepedulian itu dilakukan dengan sadar diri dan tercermin dalam kehidupan sehari-hari seperti: tidak membuang sampah sembarangan, menjaga kebersihan lingkungan, menghemat listrik, menghemat air, mengurangi penggunaan plastik dan stereofoam, mengolah sampah menjadi barang yang lebih bermanfaat, serta tidak membakar sampah.

Dalam pengembangan dan pengelolaan sarana pendukung sekolah berwawasan lingkungan SMKN 2 Semarang menyediakan tempat sampah terpisah organik, anorganik dan B3 (Bahan Berbahaya dan Beracun) serta Tempat Pembuangan Sampah (TPS) sekolah untuk menampung sampah dari masingmasing kelas dan halaman sekolah. SMKN 2 Semarang menggunakan kanopi sebagai penghubung antargedung atau bangunan, sehingga bila hujan tidak bersusah payah membawa payung kemana-mana. Lantai halaman sekolah menggunakan paving dan rumput serta dilengkapi biopori dan sumur resapan, tujuannya untuk mengurangi genangan air pada saat hujan. Kamar mandi dirawat dengan bersih, karena prinsip warga SMKN 2 Semarang bahwa indikator kebersihan suatu tempat adalah kebersihan kamar mandi. Maksudnya bila kamar mandi sudah bersih tempat yang lain biasanya juga bersih atau lebih bersih.

Penataan kantin juga teratur, rapi dan bersih terletak di bagian belakang sekolah. Kantin diharuskan meminimalisir penggunaan plastik dan kertas. SMKN 2 Semarang juga menyediakan bank sampah untuk menampung sampah anorganik dan komposter untuk mengolah sampah organik menjadi pupuk. Pupuk tersebut sebagai pupuk tanaman di sekolah, ada juga yang disumbangkan kepada sekolah atau kampung binaan untuk perawatan tanamannya. 
Prinsip program Adiwiyata berbasis partisipatif berupa keterlibatan seluruh komponen untuk berpartisipatif dan berlanjutan (KLH, 2017). Dalam pengembangan kegiatan berbasis partisipatif, SMKN 2 Semarang sudah membina tiga belas sekolah dan satu kampung binaan. Adapun kampung yang sudah dibina SMKN 2 Semarang adalah Kampung Rahayu, Kecamatan Karangturi, Semarang Timur. Kampung tersebut dipilih sebagai kampung binaan karena letaknya dekat dengan SMKN 2 Semarang, banyak siswa yang bertempat tinggal maupun kos di kampung tersebut, serta dilewatinya kampung tersebut oleh siswa ketika berangkat maupun pulang sekolah.

Kampung Rahayu merupakan kampung kecil padat penduduk, dengan rumah yang bergandengan satu dengan yang lain seperti layaknya perumahan. Di sebelah timur kampung mengalir sungai kecil yang warnanya agak kehitaman sebagai tempat mengalir limbah rumah tangga dan industri rumahan. Beberapa rumah letaknya berderetan di tepi jalan dan menghadap ke sungai

Kampung Rahayu dahulu terkenal kampung kumuh. Banyak masyarakat yang membuang sampah ke sungai atau di pinggir sungai. Sampah tersebut menyebabkan aliran sungai berbau serta membuat sungai semakin dangkal dan berwarna hitam dengan sampahsampah yang berserakan tidak teratur. Daerah tersebut terlihat kotor, kumuh, panas, dan berbau.

Selain itu aset air bersih kampung juga sulit, meskipun sudah ada sumur dan kamar mandi umum di samping sungai. Namun lambat laun masyarakat jarang yang menggunakan sumur dan kamar mandi tersebut karena kotor dan jorok, serta kurang terawat. Bahkan di sebelah kamar mandi umum tersebut dijadikan sebagai tempat pembuangan sampah. Hal ini menjadikan kesan kampung tersebut kumuh, jorok dan berbau. Sehingga setiap orang yang lewat tempat tersebut akan menutup hidungnya, bahkan memilih tidak melewati tempat tersebut. Kondisi tersebut membuat SMKN 2 Semarang tergerak untuk membina kampung tersebut agar menjadi tertata dan bersih.

Pembinaan kampung Rahayu oleh SMKN 2 Semarang tidak dilakukan setiap hari, terkadang dilakukan pada hari Jumat, sebagai program Jumat bersih atau pada sore hari sesuai kesepakatan warga kampung dan sekolah. Siswa yang dilibatkan dalam kegiataan pembinaan juga tidak seluruhnya, namun hanya sebagian siswa yang tergabung dalam SMK Hijau yang sudah terlatih untuk peduli lingkungan.

Adapun kegiatan yang dilakukan SMKN 2 Semarang dengan warga kampung berupa membersihkan sampah di sungai, menyapu lingkungan kampung, menata pot bunga dan tanaman, mengecat dan menghias pot bunga, memperbaiki sanitasi lingkungan dengan membersihkan selokan yang mengalir ke sungai serta membersihkan kamar mandi umum. Kegiatan ini bersifat sukarela dengan memanfaatkan barang bekas atau fasilitas yang ada. Baik siswa maupun warga antusias dengan kegiatan tersebut. Siswa belajar bersosialisasi dan berkreasi, sedangkan warga kampung senang dengan kampungnya yang menjadi bersih dan tertata rapi.

Dalam hal pemeliharaan tanaman, warga kampung juga diberi bantuan pupuk kompos hasil olahan sampah organik SMKN 2 Semarang. Beberapa warga dilatih dalam pembuatan dan pengolahan sampah organik menjadi kompos, pembuatan kerajinan dari barang bekas sampah anorganik, serta pelatihan menjaga kebersihan lingkungan. Tujuannya agar warga dapat meniru serta memanfaatkan sampahnya sebagai bentuk pengurangan limbah.

Menurut Mahmudah (2012) partisipasi masyarakat dalam sekolah Adiwiyata merupakan hal penting karena keikutertaannya 
dalam kebijakan sekolah akan menguntungkan masyarakat sendiri untuk turut serta dalam serangkaian kegiatan sekolah. Hal ini seperti yang dikutip dalam Kompas, 25 Oktober 2018 tentang kreatifitas siswa SMKN 2 Semarang yang bekerjasama dengan masyarakat kampung binaan untuk membuat ratusan lukisan wajah Bapak Ganjar Pranowo (Gubernur Jawa Tengah) dari kulit bawang dan pelepah pisang hingga pecahkan rekor LEPRID.

Partisipasi Adiwiyata terhadap kampung binaan sangat penting, sebab Adiwiyata merupakan program sekolah peduli dan berbudaya lingkungan yang berperan untuk mencetak generasi muda yang peduli dan cinta terhadap lingkungan. Adiwiyata sebagai pendidikan di sekolah akan diaplikasikan dalam masyarakat serta ditularkan ke seluruh keluarganya sebagai pembiasaan. Adapun imbas dari partisipasi warga sekolah terhadap kampung binaan berupa adanya contoh dan kebiasaan warga binaan dari sekolah Adiwiyata untuk menjaga dan berbudaya lingkungan.

Menurut Mahmudah (2013) strategi pemberdayaan masyarakat merupakan salah satu cara untuk menarik masyarakat agar tertarik dan ikut serta dalam kegiatan sekolah secara berlanjut. Masyarakat merasa senang bila dilibatkan dalam kegiatan kampung sebagai pengalaman dan kebersamaan. Baik warga kampung maupun warga sekolah tidak canggung bila meminta bantuan terutama untuk kebersihan lingkungan, sebab dengan lingkungan yang bersih tubuh juga akan bersih dan terjaga kesehatannya.

Tujuan kerjasama tersebut bagi warga sekolah untuk memberi kesempatan dalam mengaplikasikan pembelajaran lingkungan hidup di sekitarnya agar mengembangkan pemikirannya dalam merancang dan melakukan aksi nyata di lingkungan sekitar. Sedangkan bagi warga kampung untuk mendapatkan pengetahuan dan pengalaman mengenai pengelolaan dan kepedulian lingkungan. Harapannya dengan kerjasama membersihkan lingkungan baik warga sekolah maupun warga kampung memiliki karakter peka dan peduli lingkungan.

Keinginan tersebut tidak langsung berubah secara langsung, sebab menurut Notoatmodjo (2003) karakter peduli lingkungan terbentuk dari adanya kesadaran, ketertarikan, pertimbangan dampak, mencoba tindakan, serta berperilaku sesuai stimulus yang didapatkannya. Oleh sebab itu himbauan dan penerapan karakter peduli lingkungan tidak dilakukan sekali, namun butuh ketelatenan dan kebiasaan yang selalu diulang. Menurut Mahmudah (2015) kegiatan partisipatif Adiwiyata berjalan dengan baik karena adanya komitmen, kesadaran, dan komunikasi. Hal ini sesuai dengan prinsip partisipatif program Adiwiyata agar semua komponen dapat berperan aktif dalam upaya perlindungan dan pengelolaan lingkungan hidup secara terus menerus dan berkelanjutan (KLH, 2012).

Menurut Sulistyowati (2017) desain model pembinaan Adiwiyata berbasis partisipatif berupa: perencanaan pembinaan, pengorganisasian struktur pengurus pembinaan, pelaksanaan pembinaan, dan evaluasi pembinaan. Dengan desain model tersebut diharapkan program Adiwiyata dapat dilaksanakan secara berkelanjutan dan sesuai dengan tujuannya. Sedangkan menurut Hadi (2013) perencanaan dengan eksperimen sosial, mencoba merubah perilaku sosial dengan menterjemahkan pengetahuan ke dalam dunia praktis dan diperkaya dari pelajaran di lapangan. Oleh sebab itu, pendidikan harus memberikan arah yang benar dalam memecahkan persoalan lingkungan, baik dalam muatan kurikulum, pelatihan, pengembangan, penelitian, maupun pengabdian kepada masyarakat tentang lingkungan. Hal ini dimaksudkan agar partisipasi Adiwiyata tidak berhenti di sekolah 
saja, namun juga berimbas pada masyarakat luas.

Partisipasi warga sekolah terhadap kampung binaan sebagai stimulus untuk merubah perilaku warga masyarakat yang kurang peduli lingkungan menjadi peduli lingkungan. Sehingga perilaku peduli lingkungan tidak berhenti di sekolah saja, namun masyarakat juga peduli lingkungan. Menurut Notoatmodjo (2010) perubahan perilaku warga masyarakat bergantung pada kualitas rangsangan (stimulus) dalam berkomunikasi. Sedangkan menurut Hidayati (2014) keberhasilan program Adiwiyata merupakan hasil dari kebiasaan, pengetahuan dan pengalaman, tindakan nyata aturan sekolah yang eksplisit, dan manajemen sekolah yang mengedepankan kebutuhan lingkungan secara berkelanjutan.

Adanya pembinaan dari sekolah Adiwiyata Mandiri SMKN 2 Semarang merubah pola hidup masyarakat dalam hal pengelolaan lingkungan. Warga sudah membuang sampah di tempat sampah sesuai peruntukannya. Tempat sampah juga tersedia di depan rumahnya. Sungai menjadi lebih bersih dari sampah, kalaupun ada sedikit dan berasal dari hulu. Namun untuk memilah dan mengolah sampah hanya sebagian kecil warga yang sudah melakukan. Masyarakat sudah lebih peduli terhadap kebersihan lingkungan baik kamar mandi, sumber air, maupun lingkungan sekitar rumah. Meskipun masih ada beberapa warga yang masih membuang sampah sembarangan serta kurang peduli lingkungan. Adanya kebiasaan, contoh, himbauan untuk peduli lingkungan dari warga lain yang sudah berperilku peduli lingkungan, diharapkan dapat merubah sebagian warga yang belum tergugah untuk peduli lingkugan.

Dengan adanya pembinaan secara berlanjut diharapkan semua warga kampung dapat berperilaku peduli lingkungan yang nantinya bisa berimbas pada anak dan cucunya serta menjadi contoh bagi kampung yang lain.
Sebab perubahan perilaku seperti layaknya belajar, tergantung kualitas rangsangan (stimulus). Menurut Hosland et all dalam Notoatmodjo (2010) proses perubahan perilaku menggambarkan proses individu dalam belajar yang berupa adanya penerimaan atau penolakan stimulus (rangsang) yang diberikan, stimulus yang diterima akan dilanjutkan pada proses berikutnya untuk diolah sehingga timbul tindakan perubahan perilaku dari individu tersebut. Diagram terjadinya perubahan perilaku akibat stimulus dijelaskan dalam Gambar 1.

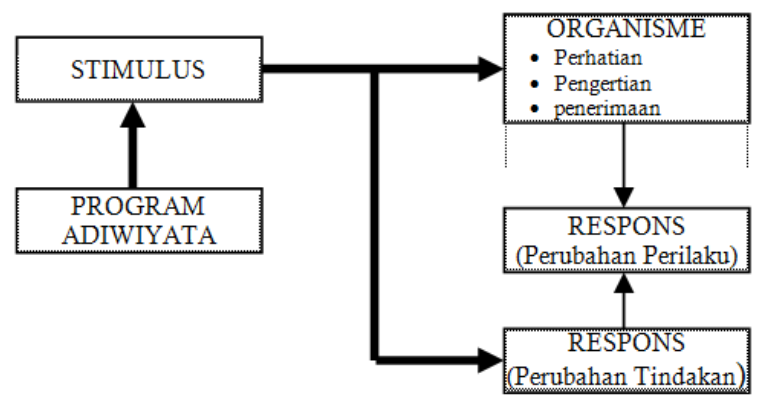

Gambar 1. Diagram perubahan perilaku akibat stimulus

Sumber: Notoatmodjo, 2010

Program Adiwiyata SMKN 2 Semarang tidak hanya merubah perilaku peduli lingkungan pada warga sekolah di lingkungan SMKN 2 Semarang, namun juga berimbas pada perubahan perilaku peduli lingkungan pada sekolah dan kampung binaan. Program Adiwiyata SMKN 2 Semarang juga merubah perilaku peduli lingkungan siswa di lingkungan masyarakat dan tempat tinggal. Menurut Meyzilia (2015) keterlibatan siswa pada program Adiwiyata mengakibatkan partisipasi siswa dalam pengelolaan lingkungan tempat tinggal, sehingga perilaku peduli lingkungan yang dibiasakan di sekolah akan terbawa dan diaplikasikan di lingkungan tempat tinggal dan masyarakat. Hasil kuisioner 97\% warga sekolah menerapkan perilaku peduli lingkungan dimanapun berada sisanya $3 \%$ hanya menerapkan perilaku peduli lingkungan 


\section{Pancasakti Science Education Journal, 4 (2), Oktober 2019- (113)}

Nanik Hidayati, Marsista Buana Putri

di sekolah yang disebabkan adanya kebijakan atau aturan sekolah tentang peduli lingkungan.

Selain perilaku peduli lingkungan, program Adiwiyata dapat meningkatkan keaktifan warga sekolah dalam kegiatan lingkungan, baik di dalam sekolah maupun di luar sekolah. Pelaksanaan program Adiwiyata dalam kegiatan partisipatif berjalan baik pada aspek context, input, process, dan product dengan ketercapaian indikator pelaksanaan perlindungan dan pengelolaan lingkungan hidup yang sangat baik (Maryani, 2014). Sekolah yang menerapkan program Adiwiyata dituntut untuk aktif dalam kegiatan lingkungan baik di dalam maupun di luar sekolah, serta menjalin kerjasama dengan sekolah lain, instansi pemerintah, serta masyarakat luas dalam rangka menularkan dan memperkenalkan program Adiwiyatanya.

Dalam suatu program pasti mengalami dukungan dan hambatan, namun hal tersebut bukan sebagai penghalang untuk tetap berlanjutnya program, sebab hambatan program sebagai evaluasi bagi keberlanjutan program berikutnya. Program Adiwiyata merupakan suatu program yang bersifat sukarela yang disertai kepedulian lingkungan secara berkelanjutan. Menurut Mahmudah (2013) program adiwiyata berbasis partisipatif merupakan suatu program yang melibatkan warga sekolah atau pihak lain secara sukarela sebagai penanaman kesadaran dan kebiasaan untuk peduli dan berbudaya lingkungan.

Adapun pendukung dari berlanjutnya program partisipasi Adiwiyata pada kampung binaan yaitu terjalinnya kerjasama dan keterbukaan antara warga SMKN 2 Semarang dengan warga Kampung Rahayu dalam menjaga kebersihan. Warga kampung siap dilibatkan untuk membantu pembuatan pot dari kaleng bekas, menata tanaman, membuat tempat pembuangan sampah, serta membersihkan sungai bersama. Antusiasme warga sekolah yang tinggi membantu warga kampung binaan dalam pengembangan dan pengelolaan lingkungan.

Sedangkan penghambat dari program tersebut antara lain keterbatasan waktu untuk membina kampung, dikarenakan banyaknya kegiatan di sekolah serta kegiatan lain di luar sekolah baik akademik maupun non akademik. Faktor penghambat yang lain dari pendanaan yang belum ada dana khusus untuk membina dan menata Kampung Rahayu, sehingga penataan taman dan pot bunga masih seadanya dengan memanfaatkan fasilitas dan barang bekas yang tersedia

\section{SIMPULAN}

Program partisipatif Adiwiyata SMKN 2 Semarang dengan membina Kampung Rahayu, Kelurahan Karangturi sudah berhasil memperbaiki kondisi lingkungan kampung serta perilaku peduli lingkungan warga, meskipun masih ada sebagian warga kampung yang acuh terhadap kondisi sekitar serta beberapa masih membuang sebagian sampahnya di sungai. Namun warga memiliki antusiasme untuk bekerjasama menata dan membersihkan lingkungan. Hal ini yang membuat semangat bagi SMKN 2 Semarang untuk terus membantu pengelolaan lingkungan di Kampung Rahayu.

Hasil pembinaan SMKN 2 Semarang terhadap Kampung Rahayu telah merubah kondisi kampung dari yang tadinya kumuh dan jorok menjadi kampung yang tertata, sungainya lebih bersih dari sebelumnya meskipun masih ada beberapa plastik dan sampah lain, namun tidak sebanyak yang dulu. Tepi sungai dan tepi jalan lebih hijau dengan banyaknya tanaman dan pot bunga dari kaleng bekas. Warga sudah membiasakan membuang sampah pada tempat yang disediakan untuk diangkut oleh mobil kebersihan.

Program Adiwiyata pada desa binaan dapat berhasil dikarenakan adanya dukungan dan kerjasama dari warga sekolah dan warga desa dalam setiap kegiatan. Program partisipatif Adiwiyata pada kampung binaan tersebut juga mengalami kendala berupa waktu 


\section{Pancasakti Science Education Journal, 4 (2), Oktober 2019- (114)}

Nanik Hidayati, Marsista Buana Putri

pembinaan yang tidak bisa setiap hari. Belum adanya dana khusus dari sekolah maupun desa, sehingga pemeliharaan dan pengelolaan lingkungan dilakukan seadanya dengan memanfaatkan fasilitas atau barang bekas yang ada.

Program Adiwiyata merupakan program sekolah untuk membentuk karakter peduli lingkungan warga sekolah. Kepedulian lingkungan sangat bermanfaat dalam pembangunan berkelanjutan, oleh sebabitu program Adiwiyata sebaiknya tetap berlanjut tidak berhenti di sekolah saja, namun diteruskan dan dikembangkan dengan sekolah atau desa di sekitarnya. Sebab desa masih membutuhkan banyak pemikiran dan masukan dari dunia pendidikan.

\section{DAFTAR PUSTAKA}

Bahrudin, Mohammad DF. 2017. Pelaksanaan Program Adiwiyata dalam Mendukung Pembentukan Karakter Peduli Lingkungan di SMA Negeri 4 Pandeglang. Jurnal Pendidikan Geografi, Volume 17, Nomor 1, April 2017.

Dave, Deeksha. (2012). Impact of Environmental Studies on the Environmentally Appropriate Behaviour and Awareness of Students of Udaipur and GautamBuddh Nagar City. Indian Journal of Environmental Education Volume 12, April 2012. ISSN: $0975-9425$.

Hadi, S.P. (2013). Manusia dan Lingkungan. Balai Pustaka: Undip.

Hidayati, Nanik. (2014). Perilaku Warga Sekolah dalam Implementasi Adiwiyata di SMK Negeri 2 Semarang. Jurnal Pendidikan Geografi, Volume 14 Nomor 1.

Mahmudah, K., Ahmad Yusuf Sobri, dan Sunarni. (2012). Partisipasi Masyarakat dalam Program Sekolah Adiwiyata Mandiri (Studi Multisitus di SDN Pandanwangi 1 Malang dan SDN Purwantoro 1 Malang). "Skripsi". Administrasi Pendidikan FIP UM.
Maryani, Ika. 2014. Evaluasi Pelaksanaan Program Sekolah Adiwiyata Ditinjau dari Aspek Kegiatan Partisipatif di SDN Ungaran 1 Yogyakarta. Jurnal Pemikiran dan Pengembangan SD, Jilid 1, Nomor 3, April 2014, hlm. 225-229.

Kementerian Lingkungan Hidup. (2017). Buku Panduan Puncak Acara Peringatan Hari Lingkungan Hidup 2017 dan Landmark Hutan Indonesia. Jakarta: Kementerian Lingkungan Hidup dan Kehutanan.

Meyzilia, Arvina. (2015). Hubungan Antara Keterlibatan Siswa pada Program Adiwiyata dengan Partisipasi Siswa dalam Pengelolaan Lingkungan Tempat Tinggal. "Skripsi" Jurusan Geografi Fakultas Ilmu Sosial UNNES.

Notoatmodjo, Soekidjo. (2010). Ilmu Perilaku Kesehatan. Jakarta: Rineka Cipta.

Sulistyowati, R., Slameto, dan Yari Dwikurnaningsih. (2017). Pengembangan Model Pembinaan Sekolah Imbas Adiwiyata Berbasis Partisipasi. Jurnal Manajemen Pendidikan. Volume: 4, No. 1 (97- 108)

Sugiyono, (2009). Memahami Penelitian Kualitatif. Bandung: Alfabeta

Tim Adiwiyata Tingkat Nasional. (2011). Panduan Adiwiyata Sekolah Peduli dan Berbudaya Lingkungan. Kerjasama Kementerian Lingkungan Hidup dengan Kementerian Pendidikan dan Kebudayaan. 